\title{
On the use of reactive power as an endogenous variable in short-term load forecasting
}

\author{
P. Jorge Santos ${ }^{1, \dagger}$, A. Gomes Martins ${ }^{2, *, \hbar}$ and A.J. Pires ${ }^{1, \S}$ \\ ${ }^{1}$ Department of Electrical Engineering, EST Setúbal/InstitutoPolitécnico de Setúbal, \\ Rua do Vale de Chaves Estefanilha 2914-508 Setúbal Portugal \\ ${ }^{2}$ Department of Electrical Engineering FCTUCIINESC, Polo 2 University of Coimbra,
} Pinhal de Marrocos, 3030 Coimbra Portugal

\begin{abstract}
SUMMARY
In the last decades, short-term load forecasting(STLF) has been the object of particular attention in the power systems field. STLF has been applied almost exclusively to the generation sector, based on variables, which are transversal to most models. Among the most significant variables we can find load, expressed as active power (MW), as well as exogenous variables, such as weather and economy-related ones; although the latter are applied in larger forecasting horizons than STLF.

In this paper, the application of STLF to the distribution sector is suggested including inductive reactive power as a forecasting endogenous variable. The inclusion of this additional variable is mainly due to the evidence that correlations between load and weather variables are tenuous, due to the mild climate of the actual case-study system and the consequent feeble penetration of electrical heating ventilation and air conditioning loads.

Artificial neural networks (ANN) have been chosen as the forecasting methodology, with standard feed forward back propagation algorithm, because it is a largely used method with generally considered satisfactory results.

Usually the input vector to ANN applied to load forecasting is defined in a discretionary way, mainly based on experience, on engineering judgement criteria and on concern about the ANN dimension, always taking into consideration the apparent (or actually evaluated) correlations within the available data. The approach referred in the paper includes pre-processing the data in order to influence the composition of the input vector in such a way as to reduce the margin of discretion in its definition. A relative entropy analysis has been performed to the time series of each variable. The paper also includes an illustrative case study. Copyright (C) 2003 John Wiley \& Sons, Ltd.
\end{abstract}

KEY WORDS: short-term load forecasting; artificial neural networks; distribution systems; inductive reactive power; relative entropy

\section{INTRODUCTION}

Load Forecasting in several time scales and specially short-term load forecasting (STLF), has greatly developed in the last few decades, mainly due to power systems management needs,

\footnotetext{
*Correspondence to: A. Gomes Martins, Department of Electrical Engineering, FCTUC/INESC, Polo 2 University of Coimbra, Pinhal de Marrocos, 3030 Coimbra Portugal.

†psantos@est.ips.pt

\$amartins@dee.uc.pt

§apires@est.ips.pt
}

Copyright (C) 2003 John Wiley \& Sons, Ltd.

Received 13 June 2002 Accepted 9 October 2002 
experienced by electric utilities (Bunn 1985; Gross and Galiana, 1987; Rahman, 1990; Lee et al., 1992; Drezga and Rhaman, 1998; Hippert et al., 2001).

Forecasting techniques and methods have developed by starting with approaches based on time-series analysis through statistical methods (SM) (Hagan and Behr, 1987; Papalexopoulos and Hesterberg, 1990). They have later developed into knowledge-based systems (KBS) (Rahman, 1990; Rahman and Hazim, 1993). More recently there have been other approaches based on fuzzy algorithms (Hsu and Ho, 1992; Mori and Kobayashi, 1996), artificial neural networks (ANN) (Lee et al., 1992; Lu et al., 1993; Caciotta et al., 1997; Charytoniuk and Chen-Mo-Shing, 2000), hybrid systems (HS) (Mohamad et al., 1996) and genetic algorithms (GA) (Maifeld and Sheblé, 1994).

The lack of information, as well as the diffuse relations between load and other relevant variables as referred by Gross and Galiana (1987), led to a clear development of these most recent methodologies.

ANN have been largely applied to STLF and particularly to the generation sector (Hippert et al., 2001). In a context where costs due to forecasting errors may be significant in this sector as Ranaweera et al. (1997), Douglas et al. (1998) and Hobbs et al. (1999) refer, ANN have presented results generally considered quite satisfactory.

In this paper ANN are applied to the distribution sector, as in Chen et al. (1996) and Fidalgo (1999). Criteria used in the analysis of forecasting error in the distribution sector are different from those used in the generation sector, nevertheless revealing a good potential for the application of ANN. Generally, the application of ANN to STLF involves three types of variables (Drezga and Rhaman, 1998; Chen et al., 1992): electrical, auxiliary and weather variables. Among the first type, active load power is frequently used the second type usually comprises nonlinear functions which are used with the purpose of helping the forecasting models to identify intrinsic load periodicity (daily, weekly and monthly); the third type includes for example, temperature, relative air humidity, nebulosity, wind speed, etc.

The relative success of the application of weather variables depends on their degree of correlation with load, thus varying with the climate of each region. In cold or warm and moist weather regions the penetration of HVAC load strongly influences the daily load diagram (LD) (Chen et al., 1996). However, STLF does not allow a clear way of establishing strong correlations of this type due the inherently slow variation of weather-related variables. Moreover, the presence of a mild weather (situation of the city of Coimbra in Portugal), and consequently weak penetration of HVAC loads (in fact, load decreases in summer, influenced by the low penetration of cooling loads (Figure 1), causes low correlation between load and weather variables. To illustrate this, a correlation diagram is presented (Figure 2) relating active power at certain hour and the average air temperature at the previous hour in a cold season (from 21-2-98 to 15-3-99). In this diagram, not only the dots do not show a clear trend, but also the $r$ factor sign is symmetrical to what could reasonably be expected, as load should increase for lower temperatures.

In this context, reactive power may be, as the paper shows, a good candidate for providing extra efficacy to load forecasting approaches. The particular load composition of the studied target substation may have a positive influence on the performance of reactive power in improving active load short-term forecast. However, the substation may also be considered typical in any urban environment, which is a favourable factor to a possible general application of this approach. One should be aware also, that reactive power data is not always available at all voltage levels in distribution networks. Frequently, SCADA systems do not acquire data of 


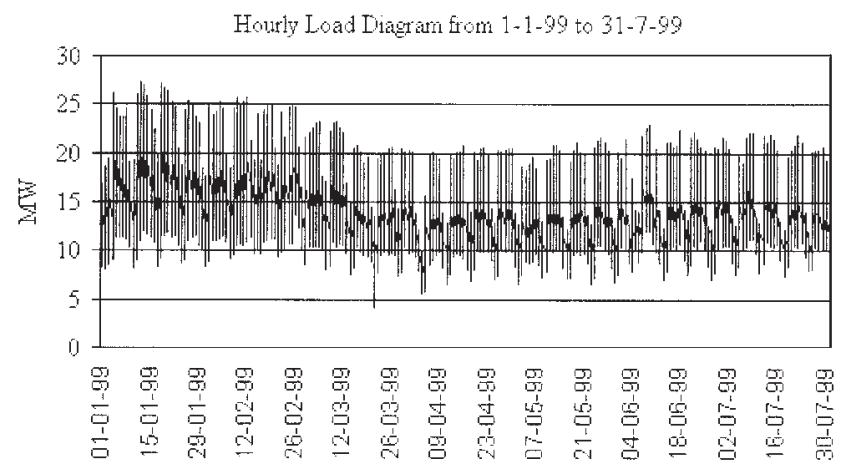

Figure 1. LD showing the decrease of summer load.

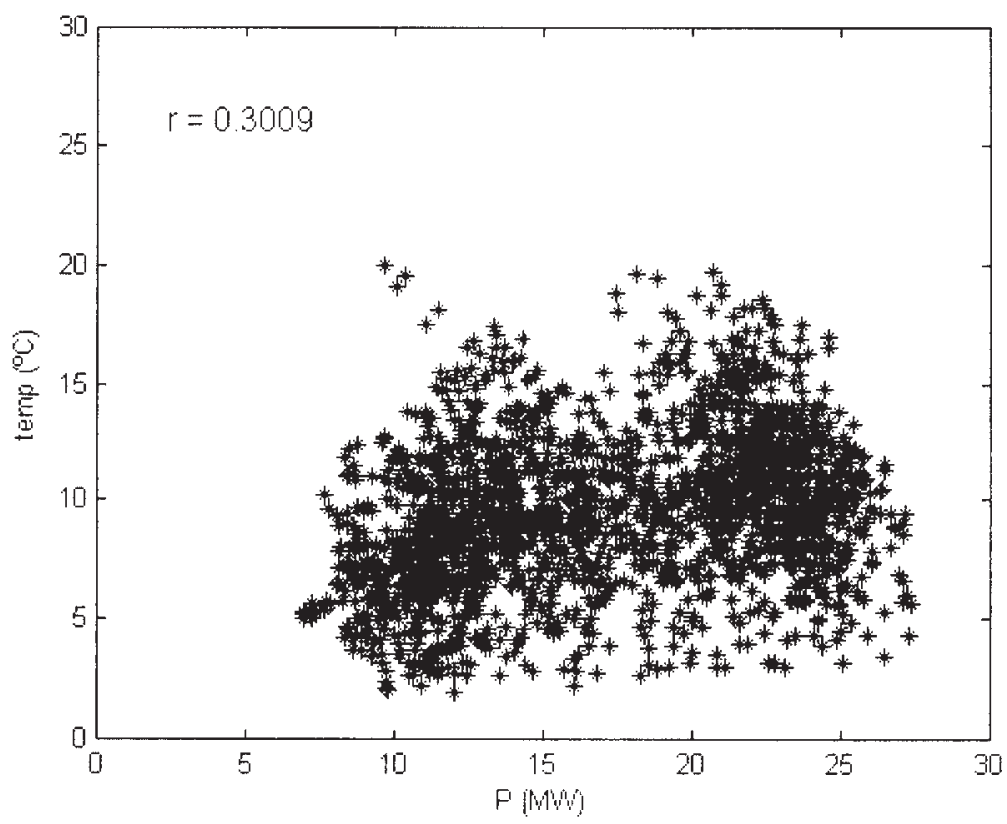

Figure 2. Scatter plot hourly diagram between active power in a certain hour $(t)$ and temperature in previous hour $(t-1)$ period.

substation outgoing feeders, as is the case of $15 \mathrm{kV}$ feeders at the target substation in the paper, which limits forecast scope to each individual transformer, as in the case study, or, in the worst case, to the substation as a whole.

Usually, the input vector to ANN applied to load forecast is defined in a discretionary way, mainly based on experience, on engineering judgement criteria and on concern about the ANN dimension, always taking into consideration the apparent (or actually evaluated) correlations within the available data. The approach referred in the paper consisted in pre-processing data in 
order to influence the composition of the input vector in such a way as to reduce the margin of discreation. At a first stage, a relative entropy analysis has been performed to the time series of each variable, as referred in Chazottes et al. (1988), according to the entropy definition.

$$
H_{n}=-\sum_{\left[\mathrm{x}_{1} \mathrm{~A} \mathrm{x}_{\mathrm{n}}\right]}^{N} \mu\left[x_{1} \ldots x_{n}\right] \ln \mu\left[x_{1} \ldots x_{n}\right]
$$

Where $\mu\left[x_{1} \ldots x_{n}\right]$ represent the probability of finding the sequence $\left[x_{1} \ldots x_{n}\right]$ in the time series of each variable. Following, a set of significant variables has been selected through principal component analysis before defining the input vector to the ANN.

The paper is divided into four sections, including this introductin: in the second section, the assembled variables are analysed as well as the correlations with load; in the third a forecasting methodology is presented, based on ANN, and experimental results are discussed; in the fourth, conclusions are drawn.

\section{DATA ANALYSIS}

One of the main concerns of distribution network management consists of predicting load in the next hour, for a specific electrical substation (ES). This information is particularly relevant in an open market context. The anticipated knowledge of consumption within this time frame allows a suitable decision support to short-term power purchase decisions and to network reconfiguration actions. It also provides the necessary information to allow the simulation of power supply interruptions in order to evaluate its consequences.

The data used in this paper, was obtained from an ES (Relvinha) (Figure 3) in the city of Coimbra, Portugal, property of EDP distribution utility. This ES is part of the city's supply network, which has the global scheme represented in Figure 4.

The ES is supplied at $60 \mathrm{kV}$ and has two transformers $(60 \mathrm{kV} / 15 \mathrm{kV} 40 \mathrm{MVA})$ supplying power to 15 output medium voltage feeders, which supply other network transformer stations $(15 \mathrm{kV} / 230 / 400 \mathrm{~V})$, spread throughout the city.

Data on two kinds of field variables were collected: electrical and weather data. They refer to the period between 21 December 1988 and 31 October 2000.

\subsection{Electrical variables}

Electricity data was collected at two voltage levels (Figure 3). At $15 \mathrm{kV}$ only average active power values were collected in each feeder. At $60 \mathrm{kV}$ level, data on the following variables was collected also on an hourly basis: active power (MW), inductive and capacitive reactive power (MVAr). Only the information relating to the $60 \mathrm{kV}$ level was used, once the purpose was to forecast the ES power values related to global consumption. It is important, at this stage, to consolidate some considerations about the LD that were obtained.

The collected data revealed the usual existence of periodicities (daily and weekly) (Figure 5), as a consequence of the cyclic nature of demand (Gross and Galiana, 1987; Rahman, 1990).

In order to classify and group the forecast results, it is useful to separate days according to similar patterns of daily LD. Hence, days were grouped as weekdays (Monday-Friday), weekends (Saturday and Sunday), holidays and special days. 


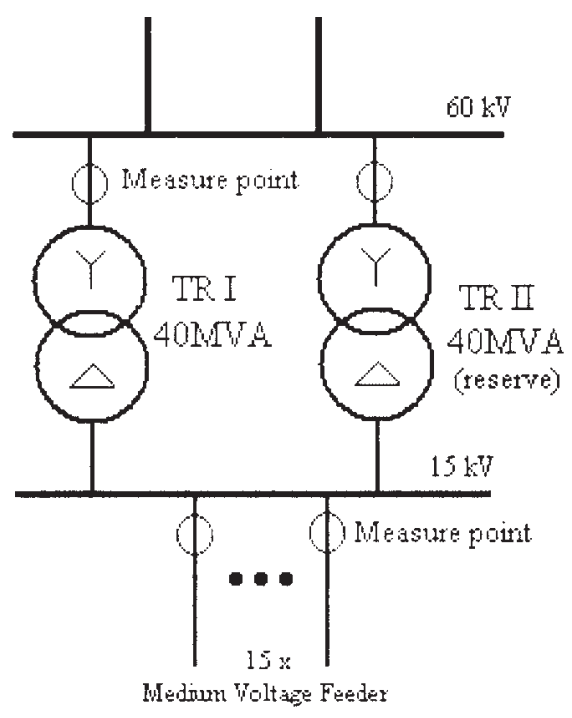

Figure 3. (ES1) Relvinha substation simplified layout.

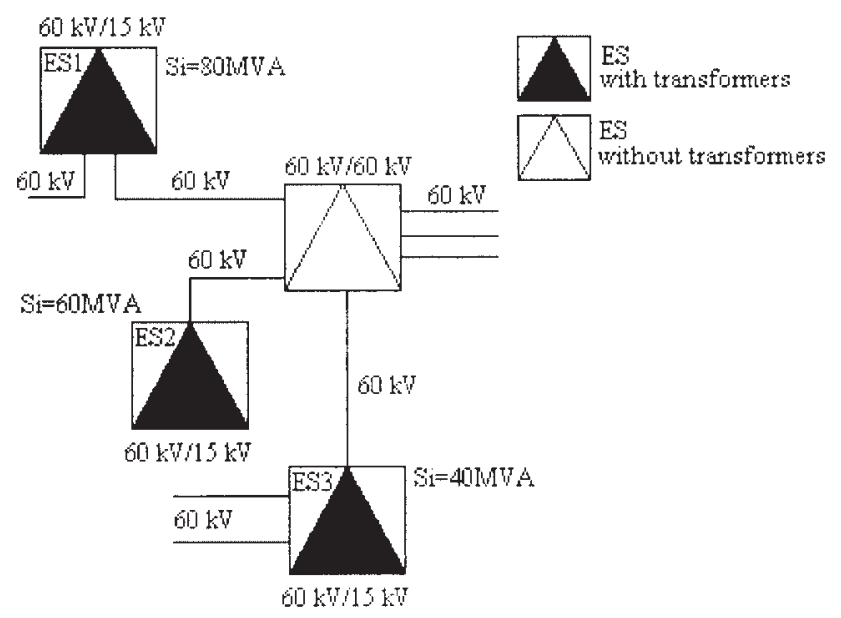

Figure 4. Simplified layout of the global medium voltage network of the city of Combra.

Special days are those that, although being weekdays, occur either immediately before or after a holiday, thus implying some decrease of economic activities (Figure 6). The behaviour of inductive reactive power is somewhat similar to active power variation with time (Figure 7). The inductive characteristic of load increases along daylight hours, becoming more resistive to the end of the day and during the night. This is a clear sign of the reduction of commercial and industrial activities. The decrease of inductive reactive power during weekends confirms what 


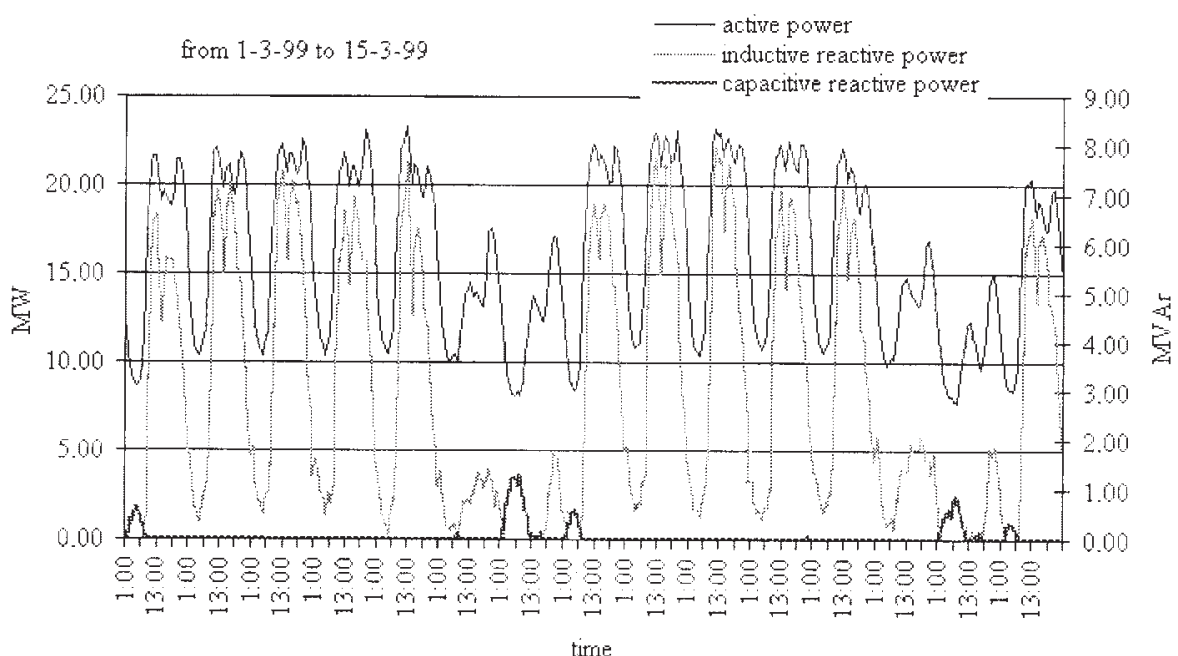

Figure 5. Typical LD 2 weeks.

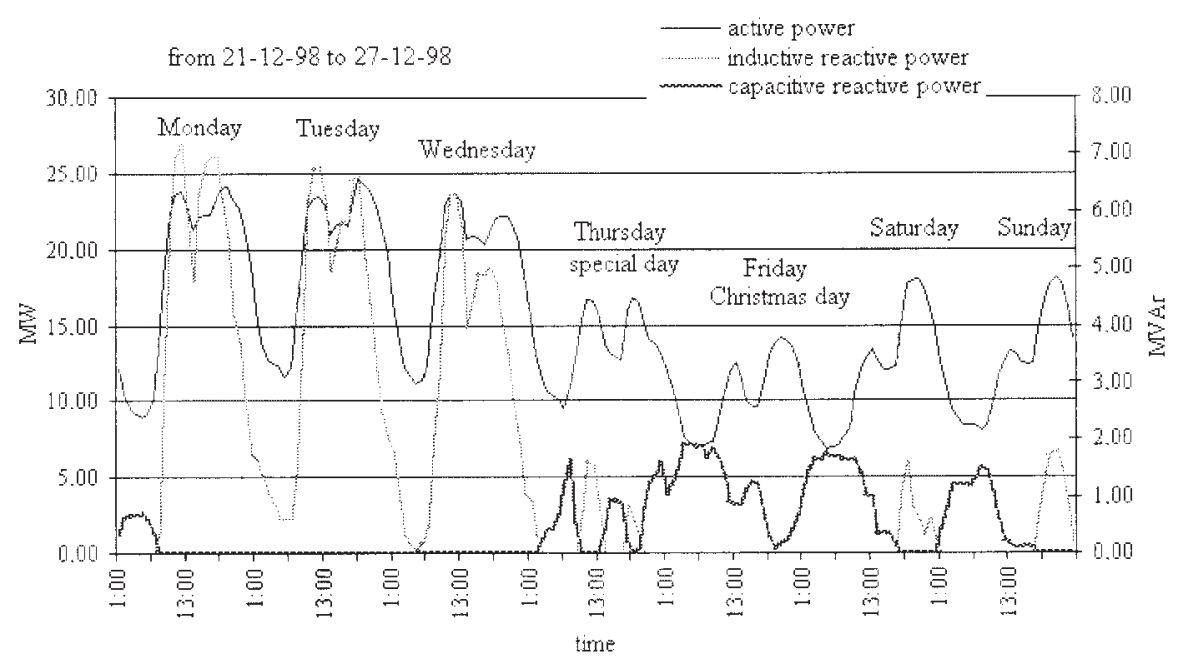

Figure 6. Weekly LD with special day.

was previously said (Figures 5 and 6). The inductive reactive power presents the disadvantage of not being always available for voltages under $60 \mathrm{kV}$.

\subsection{Weather variables}

Hourly averages were obtainted from the Portuguese Meteorology Institute from 21 December 1998 to 31 October 2000. It was possible to collect the following data: average temperature; average relative humidity; average nebulosity; average wind direction; average wind speed. 


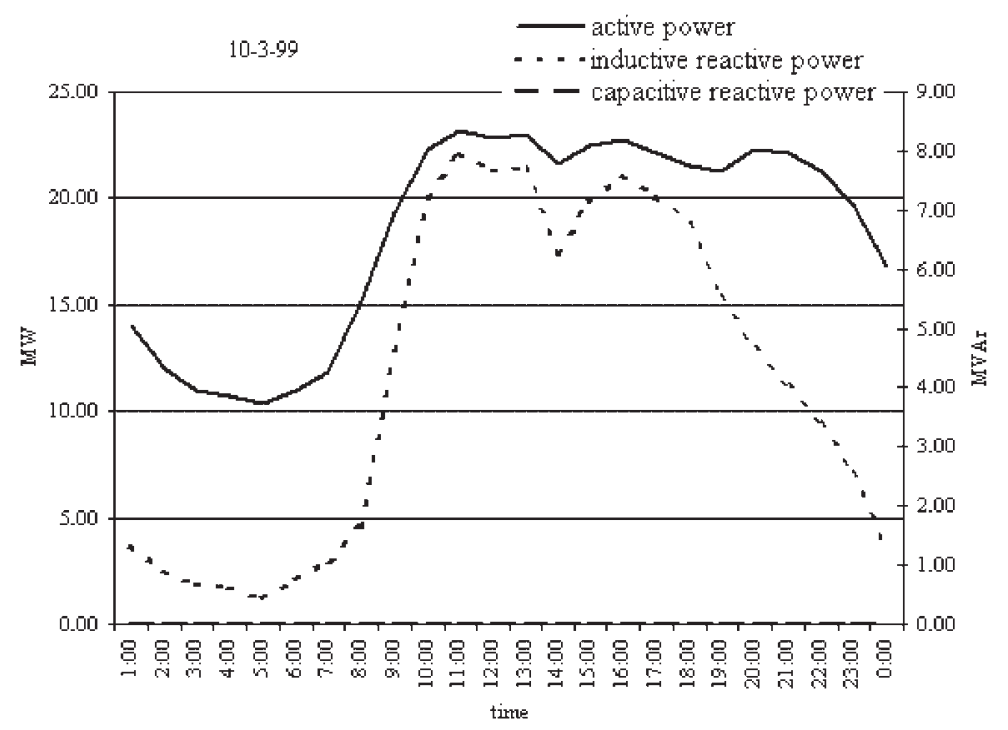

Figure 7. Typical LD working day.

\section{MODELLING AND FORECASTING METHODOLOGY}

As forecasting methodology, ANN were chosen with standard feed forward back propagation algorithm with one output, once it is only intended to forecast the next hour's active power value.

The kind of variables involved and their high degree of nonlinearity led to choosing activation functions such as hyperbolic tangent for the hidden layer, and linear to the output layer. These kinds of functions are largely used and lead to quite acceptable performances (Chen et al., 1996; Fidalgo, 1999). Several dimensions were tested for the hidden layer and five neurons have been chosen, as a higher number did not seem to positively influence the results. The size of the input vector was established as the result of correlation analyses among the different variables, in order to determine the eligible ones.

A relative entropy analysis of the time series was performed for each variable, in order to assess the dimension of each one's contribution to the input vector.

\subsection{Analysis periods}

To increase the possibility of finding significant correlations between electrical and weather variables, each year was divided in periods that were established according to the evolution of average daily temperature. This resulted in eight periods represented in Figure 8. They correspond approximately to the standard seasons, although driven by actual average temperatures, seeking to isolate periods around extreme values (roughly winter and summer) and periods of approximately constant temperature gradient (roughly autumn and spring). 


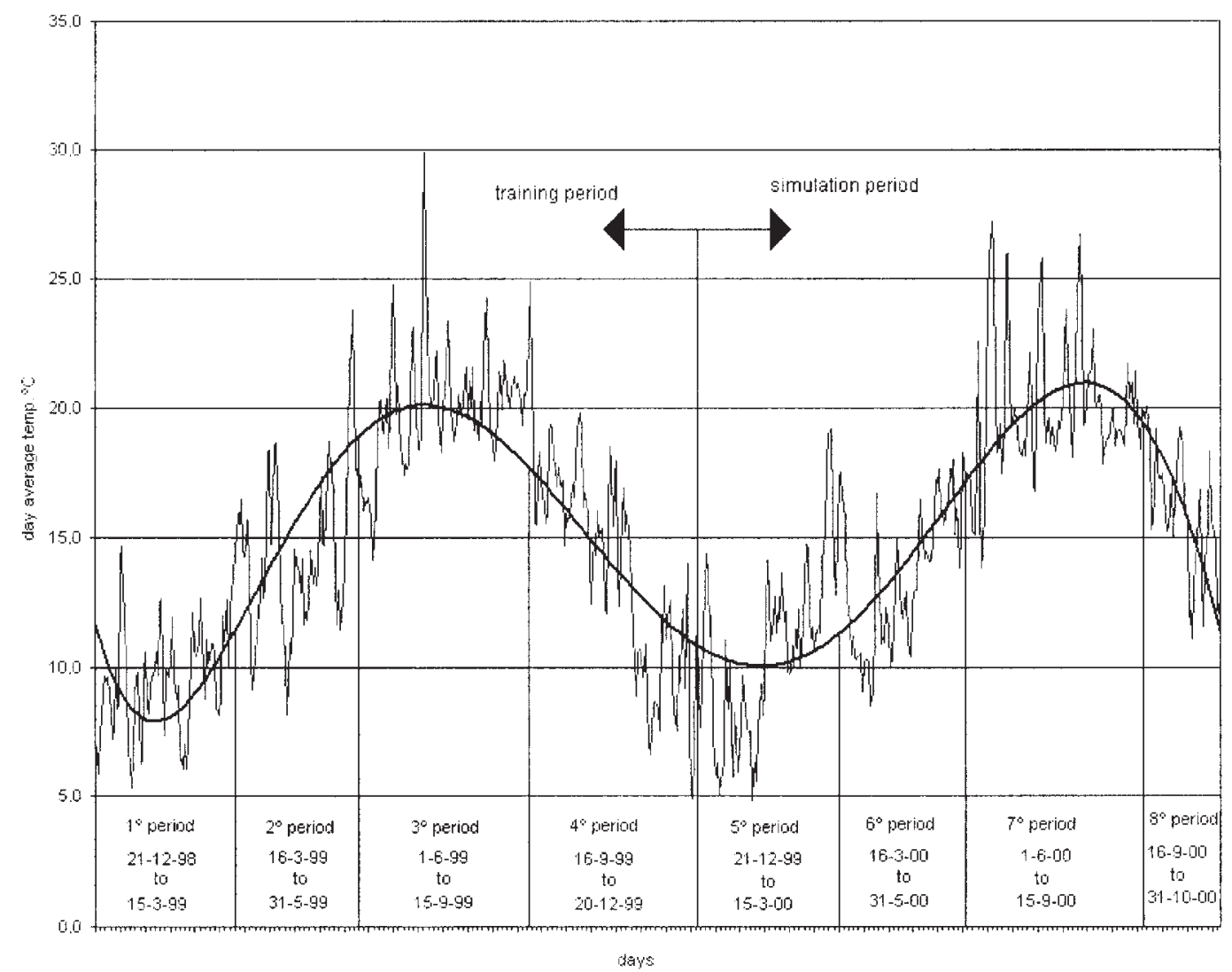

Figure 8. Periods to analyse the correlation between the variables.

\subsection{Correlation analysis}

For each of the referred periods, a correlation analysis was performed among all the electrical and weather variables. Only temperature showed to have some significant correlation with load.

Several correlation matrices were built, containing the corresponding coefficients, for different time shifts of the temperature time series in order to explore the possible delayed effect $(1,3$ and $6 \mathrm{~h})$ of temperature variations on active power load demand, due to the influence of thermal inertia of buildings on HVAC loads.

Figures 2 and 9 give evidence to the fact that there is appreciable correlation between electrical variables ( $P$ and $\mathrm{Q}_{1}$, cf. Figure 9$)$ and a feeble correlation between air temperature and active load (cf. Figure 2).

The leftmost zone of the graphics on these two figures corresponds to the lowest active power demand values, during the night periods, weekends and special days. In order to avoid the influence of these occurrences and to be able to find stronger correlation, only the weekdays of each period were considered, also excluding the first hours of each morning (from 0:00 to 9:00 $\mathrm{AM}$ ). This is consistent with the forecast goals of supporting network management decisions, 


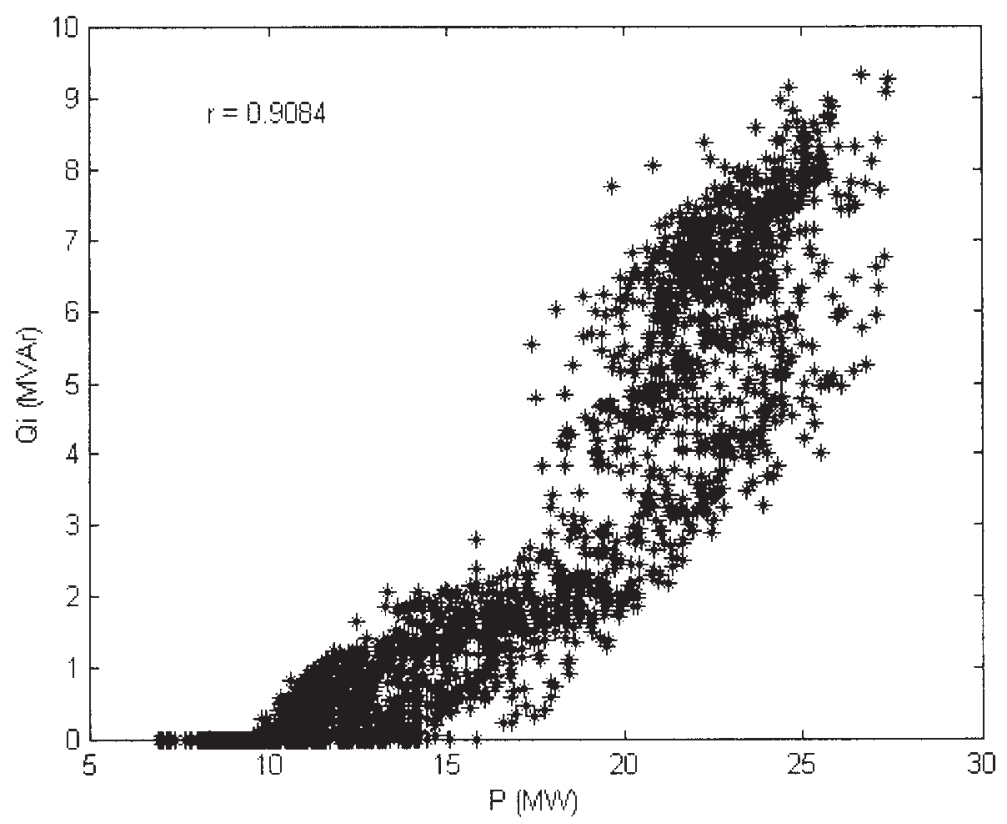

Figure 9. Scatter plot hourly diagram between active power at hour $(t)$ and reactive inductive power at hour $(t)$.

which are not critical during weekends and non-working days in general, due to lower demand values. Among the weather variables only temperature (Figure 10) presented a behaviour similar to the one expected, with negative correlation with load, thus explaining the evolution of load throughout the four seasons.

\subsection{Entropy}

Once the most significant variables to STLF were established (active power, reactive power and temperature), the dimension of the input vector had to be assessed. For this purpose, a relative entropy analysis was carried out for each chosen variable's time series-for details on the use of entropy analysis, see Chazottes et al. (1998). Different data windows were used with incrementally increasing length, entropy being computed for each, according to Equation (1) (Figure 11). A saturation criterion was used to stop the search, based on the evolution of the difference $\left(H_{n-1}-H_{n}\right)$.

The result of the entropy analysis revealed that, for the active power, the values of $\left(H_{n+1}-H_{n}\right)$ had practically no alterations for window lengths above $3 \mathrm{~h}\left(\mathrm{P}_{(t-1)} \ldots P_{(t-3)}\right)$.

In the case of reactive power, this type of saturation is obtained for a longer sequence of values, with $7 \mathrm{~h}$ previous to the forecast hours $\left(Q_{\mathrm{i}(t-1)} \ldots Q_{\mathrm{i}(t-7)}\right)$. As in the case of active power demand, for temperature the saturation is reached with three values previous to the forecast hours $\left(\operatorname{temp}_{(t-1)} \ldots \operatorname{temp}_{(t-3)}\right)$. 


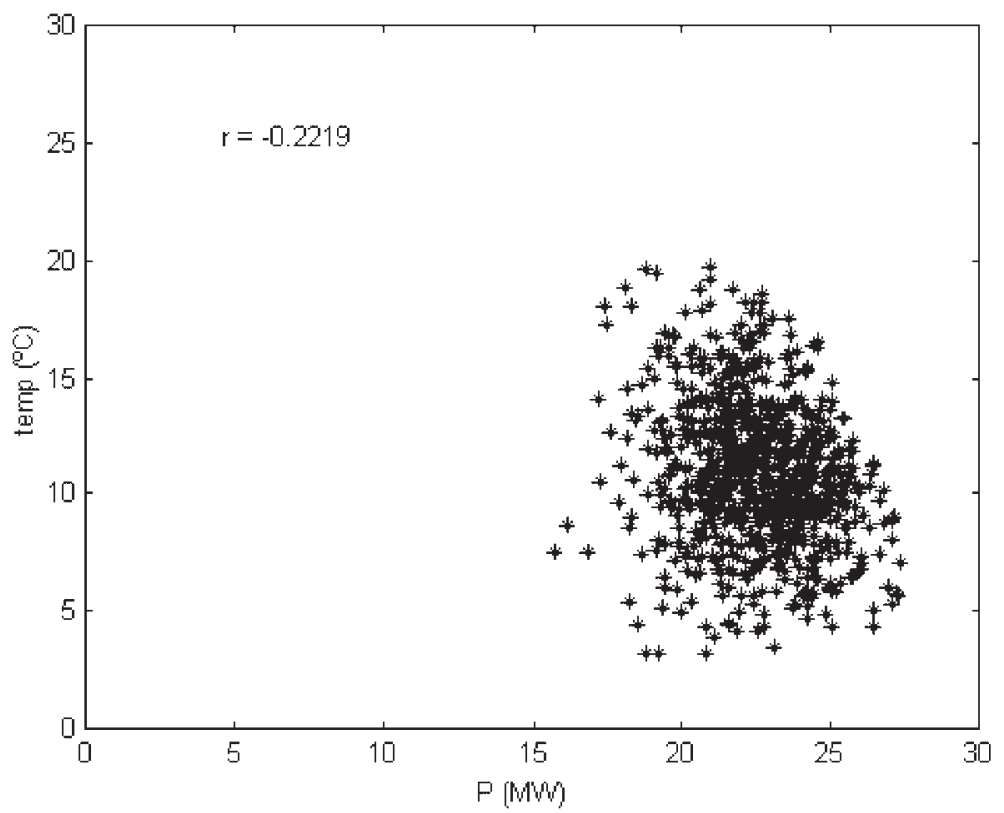

Figure 10. Scatter plot hourly diagram between active power at hour $(t)$ and temperature at hour $(t)$ from (10.00 AM to 0.00 PM) working days period 1.

$$
\begin{aligned}
& \mathrm{H}_{1} \\
& x=\left\{x_{1}, x_{2}, x_{3}, x_{4}, x_{5}, \cdots x_{x}\right\} \\
& \mathrm{H}_{2} x=\left\{x_{1}, x_{2}, x_{3}, x_{4}, x_{5}, \cdots x_{3}\right\} \\
& \mathrm{H}_{3} x=\left\{x_{1}, x_{2}, x_{3}, x_{4}, x_{5}, \cdots x_{2}\right\}
\end{aligned}
$$

Figure 11. Windows over the series.

Entropy analysis has to be performed for each variable's time series individually, which is not a guarantee per se of the validity of the input vector that may result from the simple combination of the individual results. Hence, a systematic procedure was defined, according to which several ANN were trained and tested for incrementally increasing length of the input vector length. This latter value is always a multiple of 3 , as three variables were being used, with an incremental step of one each. Figure 12 also shows the results obtained by means of this procedure, plotting the mean absolute percentage error (MAPE) against the input vector dimension. The MAPE trend line is also plotted. The MAPE for the ANN designed with the input vector composed with 3-7-3 ( $P$ - $\mathrm{Q}_{\mathrm{i}}$-temp) values previous to the forecast hour, as resulted from the entropy analysis is also shown, corresponding to the value $13(3+7+3)$ in the $X$-axis. Its relative position in the plot reveals that the input vector as defined with the help of the entropy analysis is not outside acceptable error bounds. Hence, it may be used, at least in this 


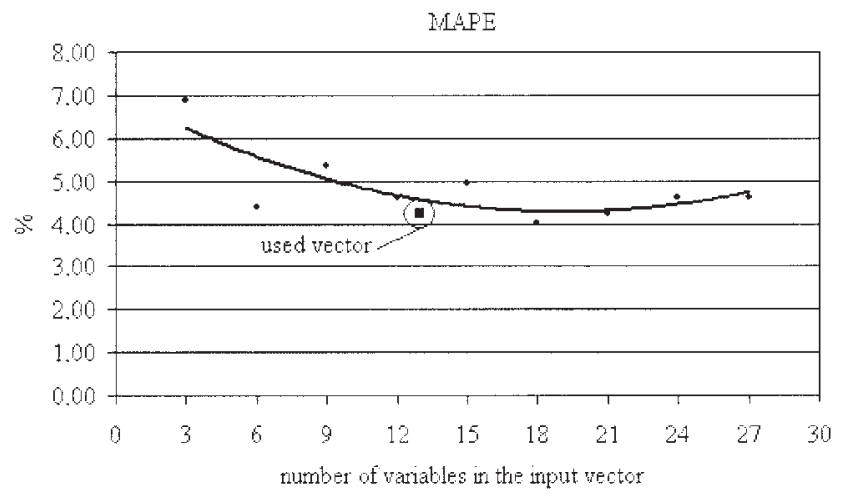

Figure 12. Mean absolute percentage error for different ANN.

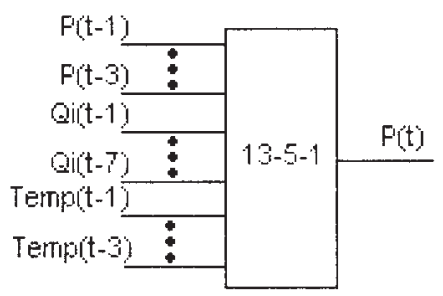

Figure 13. Input vector.

case, as a rationale for driving the composition of the input vector, thus reducing the discretion of the analyst intervention in the modelling phase.

The final input vector and ANN were defined as depicted in Figure 13. The input vector was subsequently normalized, before the training and test phases of the ANN. It should be noted that the training, test and validation sets of values have all been defined as completely independent of each other. The simulations that have been performed in order to evaluate the ANN with values not involved in model tuning, have also been based on an additional independent set of values.

\subsection{Experimental results}

For the training testing and validation procedures, periods $1-4$ were used and for simulation, periods 5-8 were used (cf. Figure 8).

The most common way of measuring performance, in models with similar methodologies, as referred by Hippert et al. (2001), is based on the MAPE. Nevertheless, and still also according to this author, it is advisable to use other parameters (as the standard deviation (STDV), among others), in order to be able to obtain a better compromise.

It is usually not possible to find a way of comparing the performances of the models reported in the literature once both the periods under analysis, and the goals are not similar. Even so, it is a common approach to classify the results according to grouping of days, weeks and months. 
In face of the several values of MAPE published in the literature, an error margin of $2-5 \%$ for a certain period is usually accepted as adequate, in what concerns STLF models based on ANN. In this paper, the results were grouped according to the type of day and period, as defined previously.

In order to provide a better insight to the performance of the model than a simple MAPE value can provide, two sets of additional parameters are presented. First, Tables I and II contain the: mean absolute deviation (MAD), standard deviation (STDV), and the average power demand in the period $\left(\mathrm{P}_{\mathrm{av}}\right)$. Secondly, to specifically measure the error, also the mean percentage error (MPE), the mean squared error (MSE), the residual standard error (RSE), the mean error (ME) and the absolute deviation are shown in Tables III and IV besides the MAPE.

The results obtained can be considered fairly satisfactory. The generalization capability of the ANN can be testified when it is applied to different types of weekdays (Figure 14). weekends (Figure 15) and special days (Figure 20).

In order to visualize the ANN performance, several typical LD for different periods (Figures 16-19) are also presented.

Table I. Next hour load forecast-comparative data analysis (working days).

\begin{tabular}{lcccccccc}
\hline Period & \multirow{2}{*}{$\begin{array}{l}\text { No. of } \\
\text { days }\end{array}$} & \multicolumn{3}{c}{ Target } & & \multicolumn{3}{c}{ Forecasting } \\
\cline { 3 - 5 } \cline { 7 - 9 } & & STD V (MW) & MAD (MW) & $P_{\text {av }}(\mathrm{MW})$ & & STD V (MW) & MAD (MW) & $P_{\text {av }}(\mathrm{MW})$ \\
\hline 5 & 57 & 4.76 & 4.04 & 17.59 & & 4.71 & 4.02 & 17.40 \\
6 & 50 & 3.21 & 2.78 & 16.02 & & 3.24 & 2.84 & 16.01 \\
7 & 70 & 3.42 & 2.04 & 15.91 & & 3.37 & 1.99 & 15.76 \\
8 & 32 & 3.63 & 3.25 & 15.83 & & 3.60 & 3.20 & 15.80 \\
\hline
\end{tabular}

Table II. Next hour load forecast-comparative data analysis (non-working days).

\begin{tabular}{lcccccccc}
\hline Period & \multirow{2}{*}{$\begin{array}{l}\text { No. of } \\
\text { days }\end{array}$} & \multicolumn{3}{c}{ Target } & & \multicolumn{3}{c}{ Forecasting } \\
\cline { 3 - 5 } \cline { 7 - 9 } & & STD V (MW) & MAD (MW) & $P_{\text {av }}(\mathrm{MW})$ & & STD V (MW) & MAD (MW) & $P_{\text {av }}(\mathrm{MW})$ \\
\hline 5 & 28 & 3.48 & 2.76 & 14.16 & & 3.25 & 2.51 & 13.97 \\
6 & 24 & 2.02 & 1.66 & 12.76 & & 1.91 & 1.54 & 12.73 \\
7 & 36 & 1.87 & 1.46 & 12.08 & & 1.75 & 1.33 & 12.09 \\
8 & 13 & 1.83 & 1.52 & 11.76 & & 1.79 & 1.041 & 11.87 \\
\hline
\end{tabular}

Table III. Next hour load forecast-error results (working days).

\begin{tabular}{lcccccrc}
\hline Period & No. of days & ME (MW) & MAD (MW) & MSE (MW $)$ & RSE (MW) & MPE (\%) & MAPE (\%) \\
\hline 5 & 57 & 0.19 & 0.63 & 0.69 & 0.83 & 0.97 & 3.76 \\
6 & 50 & 0.01 & 0.7 & 1.20 & 1.10 & -0.16 & 4.50 \\
7 & 70 & 0.15 & 0.52 & 0.56 & 0.75 & 0.76 & 3.33 \\
8 & 32 & 0.04 & 0.5 & 0.49 & 0.70 & 0.07 & 3.27 \\
\hline
\end{tabular}


Table IV. Next hour load forecast-error results (non-working days).

\begin{tabular}{lccccccc}
\hline Period & No. of days & ME (MW) & MAD (MW) & MSE $\left(\mathrm{MW}^{2}\right)$ & RSE (MW) & MPE (\%) & MAPE (\%) \\
\hline 5 & 28 & 0.19 & 0.72 & 1.00 & 1.00 & 0.78 & 4.96 \\
6 & 24 & 0.02 & 0.57 & 0.59 & 0.77 & -0.13 & 4.47 \\
7 & 36 & -0.01 & 0.42 & 0.32 & 0.56 & -0.33 & 3.49 \\
8 & 13 & -0.11 & 0.50 & 0.45 & 0.67 & -1.21 & 4.13 \\
\hline
\end{tabular}

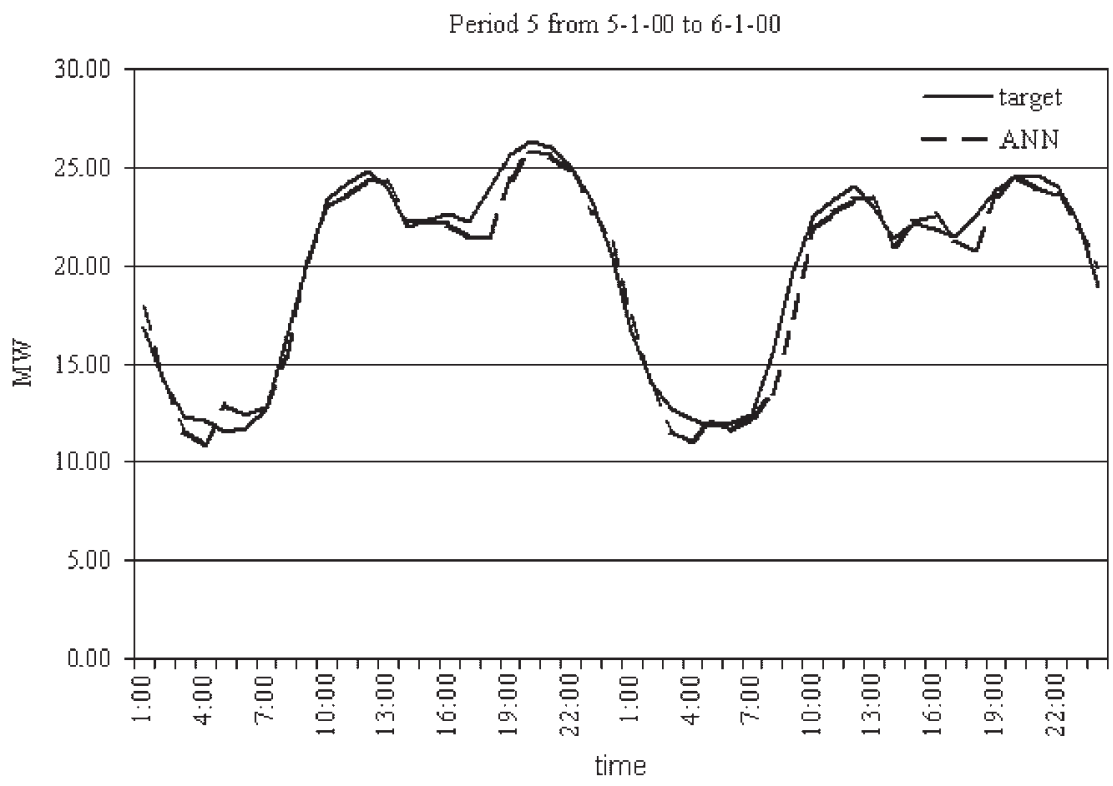

Figure 14. Typical LD of a working day in a winter period.

\section{CONCLUSIONS}

STLF assumes great importance in electricity distribution network management, particularly in the context of unbundling and subsequent liberalization processes applied to power systems worldwide. In fact, STLF may be a crucial activity either if distributors are also retailers or if they are confined to network management, as the activities of energy purchasing and network reconfiguration. for example, clearly illustrate.

The use of reactive power as an input variable to ANN applied to active load forecast has been demonstrated to be an adequate choice among the endogenous variables usually available through distribution SCADA systems, especially in cases where the correlation of active power with exogenous variables is not very significant, as happens with air temperature in the used case study. The main drawback of modelling based on reactive power is the possible unavailability of data on this variable for lower voltage levels, particularly when more disaggregated consumption data is available for active power and forecasts would be useful at that level as well. 


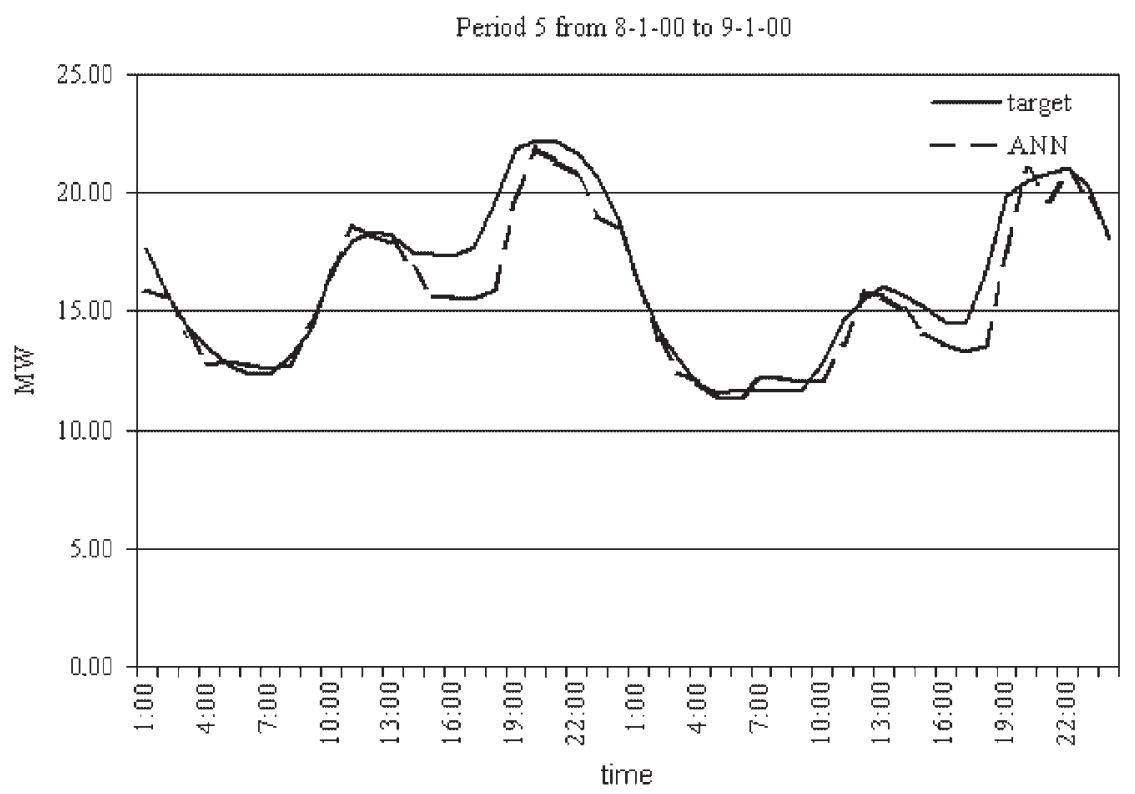

Figure 15. Typical weekend LD of a winter period.

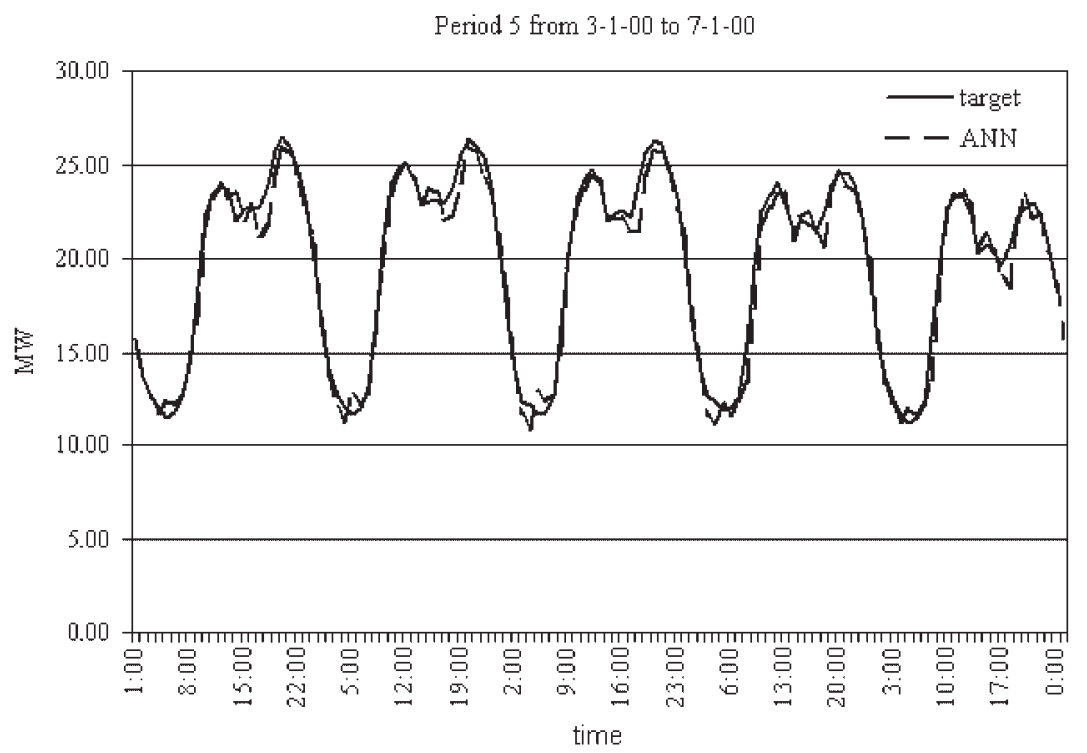

Figure 16. Typical week LD period 5.

Designing ANN-based models for load forecasting is usually associated to a certain level of discretion by the analyst, since the input vector is commonly defined according to intuition, experience and engineering judgement, complemented with extensive experimentation. In the 


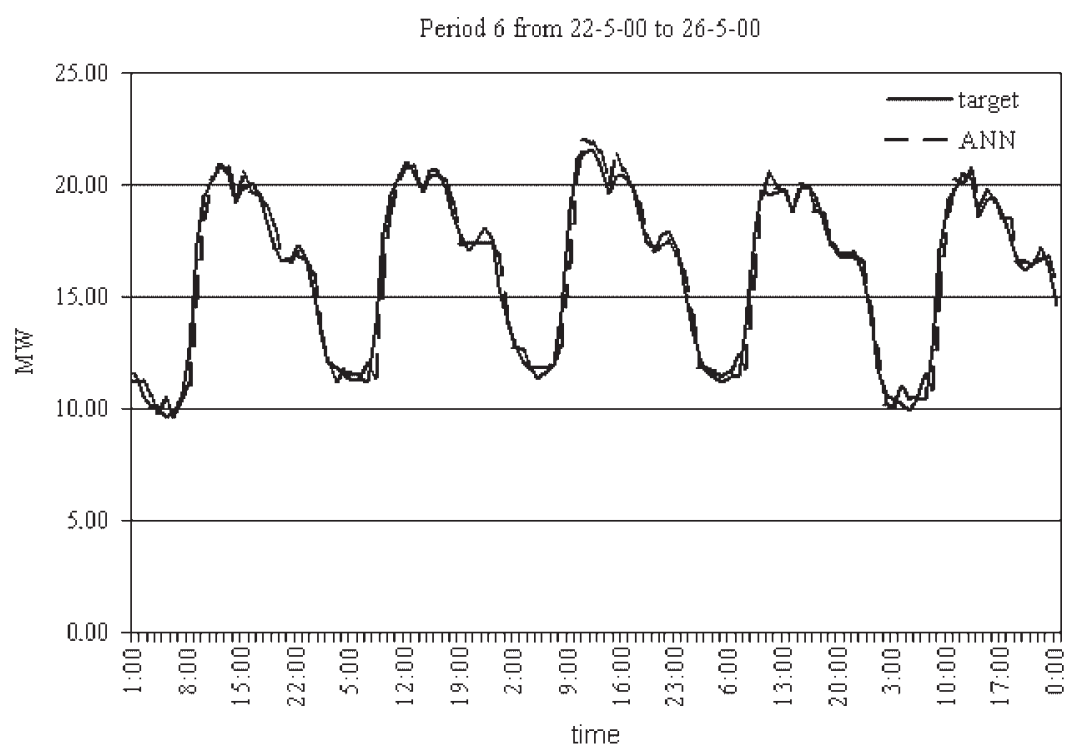

Figure 17. Typical week LD period 6.

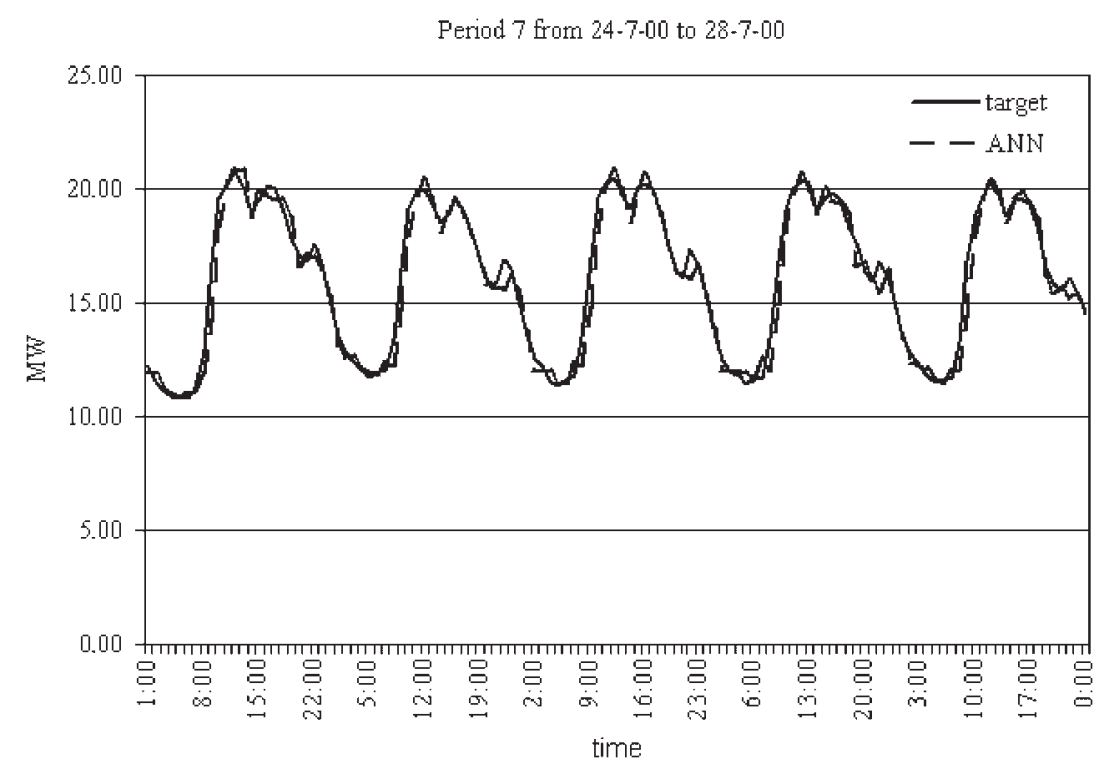

Figure 18. Typical week LD period 7.

paper, the concept of relative entropy has been used in order to try to reduce the level of discretion, as it helps defining an alleged appropriate length of the time window for each variable to be included in the input vector to the ANN used to predict the next hour's active 
Period 8 from $23-10-00$ to $27-10-00$

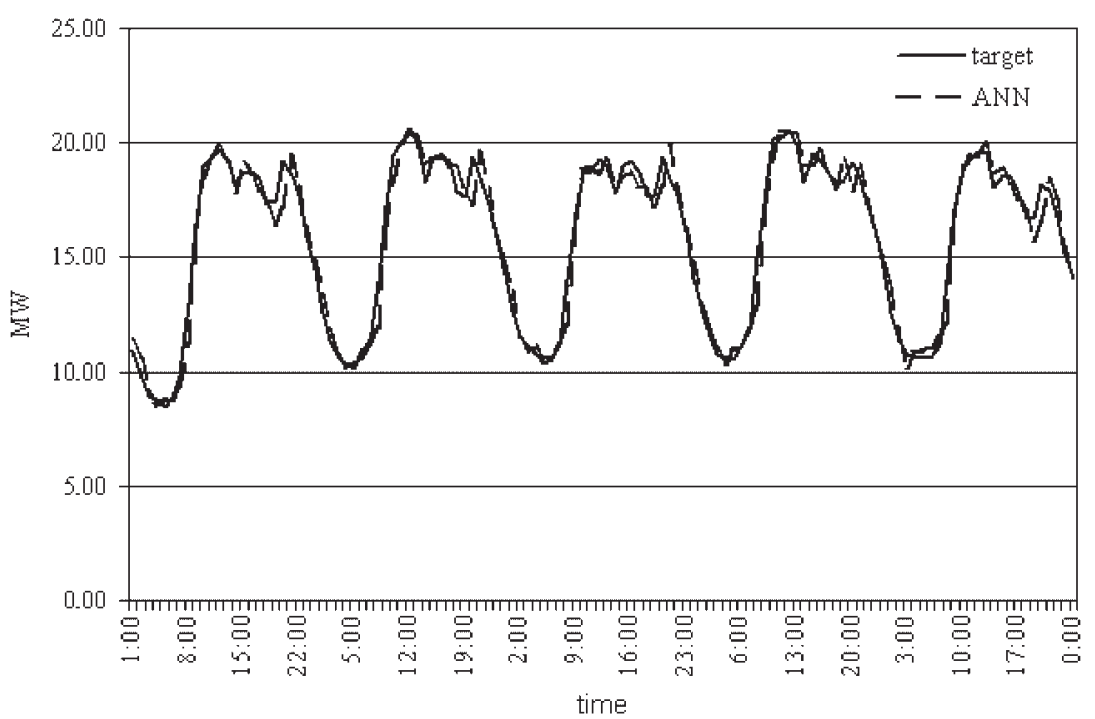

Figure 19. Typical week LD period 8.

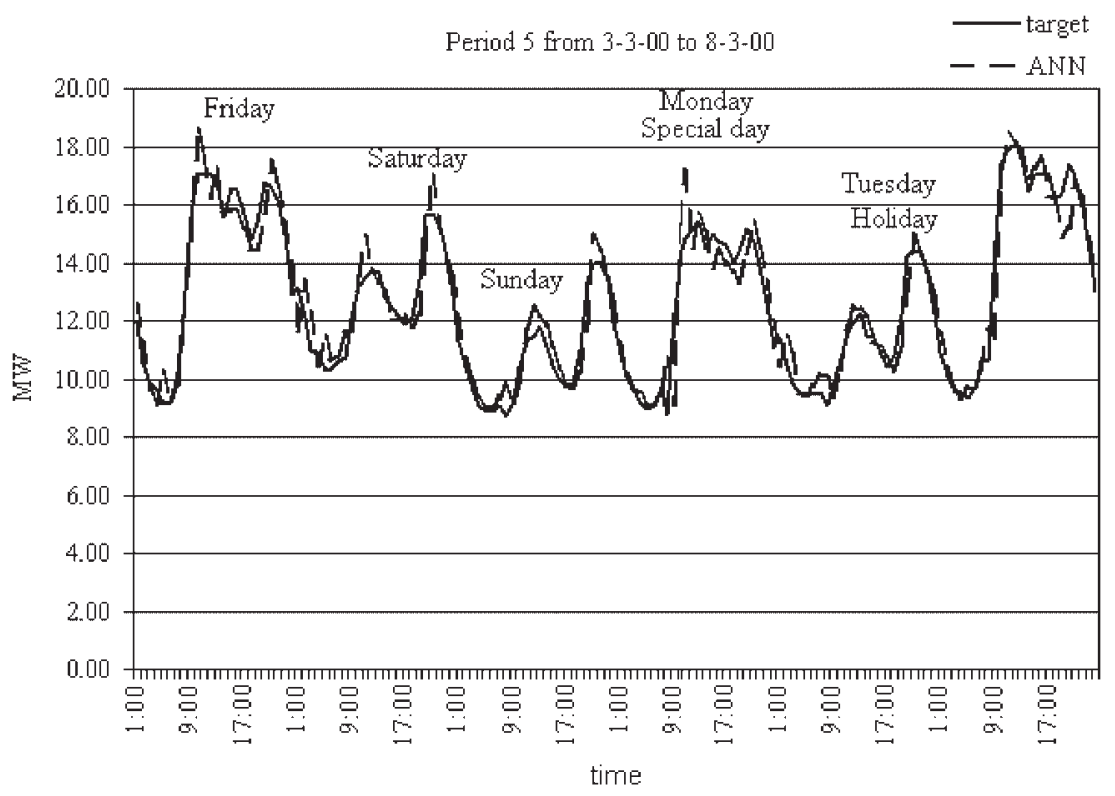

Figure 20. Typical week LD with special day.

load. Also, an appropriate level of the ANN complexity has been sought for, in order to avoid the possibility of overfitting due to the relatively modest length of the available time-series data (a little less than 2 years in the used case study). 
The obtained MAPE compare well with the average intervals available for other distribution systems, although other types of forecasting error indicators that have been quantified in the paper cannot be compared because they do not usually appear in the literature.

\section{ACKNOWLEDGEMENTS}

The authors would like to tank: Professor João Martins from the Department of Electrical Engineering ESTSetúbal for his kind advice, and to EDP Distribuição Direç̧ão do Centro and IM-Instituto de Meteorologia de Portugal for all the provided data.

\section{REFERENCES}

Bunn DW, Farmer ED. 1985. Comparative Models for Electrical Load Forecasting. Wiley: New York: 13-30.

Caciotta M, Lamedica R, Cencelli V, Prudenzi A, Sforna M. 1997. Application of artificial neural networks to historical data analysis for short-term electric load forecasting. European Transactions on Electrical Power 7(1):49-56.

Charytoniuk W, Chen Mo-Shing, 2000. Very short-term load forecasting using artificial neural networks. IEEE Transactions on Power Apparatus and Systems 15(1):263-268.

Chazottes J, Floriani E, Lima R. 1998. Relative entropy and identification of Gibbs measures in dynamical systems. Journal of Statistical Physics 90(3/4):697-725.

Chen Shin-Tzo, David C, Moghaddamjo A. 1992. Weather sensitive short-term load forecasting using nonfully connected artificial neural network. IEEE Transactions on Power Apparatus and Systems 7(3):1098-1105.

Chen C, Tzeng Y, Hawang J. 1996. The application of artificial neural networks to substation load forecasting. Electric Power Systems Research 38:153-160.

Douglas A, Breiphol A, Lee F, Adapa R. 1998. Risk due to load forecast uncertainity in short term power system planning. IEEE Transactions on Power Systems 13(4):1493-1499.

Drezga I, Rhaman S. 1998. Input variable selection for ANN-based short term load forecasting. IEEE Transactions on Power Systems 13(4):1238-1244.

Fidalgo J. 1999. Previsão de carga em saidas de Subestaçòes-resultados preliminares. ELAB ' $994^{\circ}$ encontro Luso-AfroBrasileiro de Planejamento e Exploracão de Redes de Energia, 339-348.

Gross G, Galiana F. 1987. Short term load forecasting. IEEE Proceedings 75(12):1558-1573.

Hagan M, Behr S. 1987. The time series approach to short term load forecasting. IEEE Transactions on Power Systems 2(3):785-791.

Hippert H, Pereira C, Souza R. 2001. Neural networks for short-term load forecasting: A review and evaluation. IEEE Transactions on Power Systems 16(1):44-55

Hobbs F, Jitprapaikulsaran S, Martululam D. 1999. Analysis of the value for unit commitment of improved load forecasts. IEEE Transactions on Power Systems 14(4):1342-1348.

Hsu Y, Ho K. 1992. Fuzzy expert systems: an application to short term load forecasting. IEEE Proceedings-C 139(6):471-477.

Lee K, Cha Y, Park J. 1992. Short-term load forecasting using an artificial neural network. IEEE Transactions on Power Systems 7(1):124-132.

Lu C, Wu H. Vemuri S. 1993. Neural network based on short term load forecasting IEEE Transactions on Power Systems 8(1):336-342.

Maifeld T, Sheblé G. 1994. Short-term load forecasting by a neural network and refined genetic algorithm. Electric Power Systems Research 31:147-152.

Mohamad E, Mansour N, El-Debeiky S, Mohamad K, Rao N, Ramakrisha G. 1996. Results of Egyptian unified grid hourly load forecasting using an artificial neural network with an expert system interface. Electric Power Systems Research 39:171-177.

Mori H, Kobayashi H. 1996. Optimal fuzzy inference for short term load forecasting. IEEE Transactions on Power Systems 11(1):390-396.

Papalexopoulos A, Hesterberg T. 1990. A regression-based approach to short term system load forecasting. IEEE Transactions on Power Systems 5(4):1535-1544.

Rahman S. 1990. Formulation and analysis of a rule-based short-term load forecasting algorithm. IEEE Proceedings 78(5):805-816.

Rahman S, Hazim, O, 1993. A generalized knowledge-based short-term load forecasting technique. IEEE Transactions on Power Systems 8(2):508-514.

Ranaweera D, Karady G, Farmer R. 1997. Economic impact analysis of load forecasting. IEEE Transactions on Power Systems 12(3):1388-1392. 